\title{
Time flies when we read taboo words
}

\author{
JASON TIPPLES \\ University of Hull, Hull, England
}

\begin{abstract}
Does time fly or stand still when one is reading highly arousing words? A temporal bisection task was used to test the effects of sexual taboo words on time perception. Forty participants judged the duration of sexual taboo, high-arousal negative, high-arousal positive, low-arousal negative, low-arousal positive, and category-related neutral words. The results support the hypothesis that sexual taboo stimuli receive more attention and reduce the perceived time that has passed ("time flies") - the duration of high sexual taboo words was underestimated for taboo-word stimuli relative to all other word types. The findings are discussed in the context of internal clock theories of time perception.
\end{abstract}

Emotion can affect our experience of time in different ways, determining whether we describe a passage of time as "standing still" or "flying by." Research has shown that, when attention is diverted from the process of time keeping, the duration of events is experienced as lasting less time (i.e., "time flies"; see, e.g., Zakay \& Fallach, 1984). Given that emotional stimuli can receive more attention (e.g., MacKay \& Ahmetzanov, 2005; Schimmack, 2005; Tipples \& Sharma, 2000), it is somewhat surprising that a number of recent studies (Droit-Volet, Brunot, \& Niedenthal, 2004; Effron, Niedenthal, Gil, \& Droit-Volet, 2006; Gil, Niedenthal, \& Droit-Volet, 2007; Mondillon, Niedenthal, Gil, \& Droit-Volet, 2007; Tipples, 2008) have shown that individuals perceive the duration of facial expressions of emotion as lasting longer than facial expressions that are neutral. The present study examines the effect of emotional word stimuli on time perception, the hypothesis being that taboo word stimuli receive more attention and, thus, lead to an underestimation of perceived time.

Droit-Volet et al. (2004) used a temporal bisection task to study the effects of facial expressions on time. Participants were asked to estimate whether the durations of angry, happy, sad, and neutral facial expressions were more similar to either a short $(400 \mathrm{msec})$ or long $(1,600 \mathrm{msec})$ interval that they had learned earlier in the experiment. The expressions were presented for seven durations that ranged from short to long. Participants consistently overestimated the duration of the angry, happy, and sad facial expressions relative to the neutral expressions. Specifically, participants produced a higher proportion of "long" responses for emotional facial expressions than for neutral expressions, and the bisection point (BP; comparison duration giving rise to $50 \%$ of the "long" responses) decreased accordingly. The findings were interpreted within the context of internal clock theories of time processing (e.g., Gibbon, Church, \& Meck, 1984). In general, these models include an arousal-sensitive pacemaker (Wearden, Phil- pott, \& Win, 1999) that sends pulses (or units of elapsed time) to an accumulator via an attention-controlled switch that closes with the onset of the stimulus and opens again after offset. In the final stage, the presented duration is compared with the representation of the learned duration (the short and long durations in the bisection task) that is stored in reference memory. Arousal and attention are thought to affect different mechanisms within the internal clock. Increased arousal is thought to accelerate the rate of the pacemaker, leading to a greater number of counted units of time and, consequently, to an overestimation of time. Attending to nontemporal information (e.g., secondary task information) is thought to open the switch, leading to a loss of pulses entering the accumulator and, consequently, to an underestimation of time (e.g., Burle \& Casini, 2001). Droit-Volet et al.'s study supports the idea that observing facial expressions increased the rate of an internal pacemaker. Specifically, overestimation was greatest for faces appearing more highly aroused (angry facial expressions) than for faces appearing less aroused (i.e., sad facial expressions).

Both underestimation and overestimation have been recorded for other types of emotional stimuli. Noulhiane, Mella, Samson, Ragot, and Pouthas (2007) examined the influence of emotional sounds on time perception. Participants were asked either to reproduce (Experiment 1) or to provide a verbal estimate (Experiment 2) of the duration of emotional auditory stimuli that lasted between 2 and 6 sec. Participants consistently judged emotional sounds as longer than neutral sounds. Furthermore, overestimation was greatest for negative sounds. However, in keeping with the idea of emotion capturing attention, participants more consistently underestimated the duration of high-arousal sounds than they did the duration of low-arousal sounds. A separate study (Angrilli, Cherubini, Pavese, \& Manfredini, 1997), which examined the effects of emotional images on time perception, found 
that time estimates depended on both the valence and arousal of the stimuli. In particular, participants judged the duration of low-arousal negative pictures as shorter than the duration of low-arousal positive pictures, but they judged the duration of high-arousal negative pictures as longer than the duration of high-arousal positive pictures. This interaction effect was explained in terms of a double mechanism: More attentional resources were allocated to the processing of the more interesting low-arousal negative slides compared with the low-arousal positive slides; consequently, time was underestimated, because fewer attentional resources were available for time estimation. Overestimation of high-negative-arousal slides relative to high-positive-arousal slides was thought to reflect an emotion-driven appetitive-aversive process. Because participants were unable to avoid negative arousing pictures, those pictures were perceived as lasting "too long" (overestimation due to aversive motivation), whereas highly arousing positive slides were perceived as lasting "not long enough" (underestimation due to appetitive motivation). In summary, how arousal and valence affect time perception is dependent on whether the stimuli are pictures or sounds.

How might emotional word stimuli affect time perception? Studies into the effects of emotional word stimuli on attention have recorded attentional bias for taboo words, but not for other types of words (e.g., Anderson, 2005; Arnell, Killman, \& Fijavz, 2007; MacKay et al., 2004). For example, accuracy at identifying color names in rapid serial visual presentation is reduced if the words are preceded by arousing, sexually explicit, taboo words but not if they are preceded by negative, positive, or threatening words (Arnell et al., 2007). Typically, emotional (nontaboo) words do not bias attention (but see Sharma \& McKenna, 2001) unless the emotional words are relevant to the ongoing concerns of the individual being tested (for a review of the supporting evidence, see Williams, Mathews, \& MacLeod, 1996).

In summary, there is evidence that taboo-word stimuli are particularly effective at capturing attention. To reiterate, if such stimuli receive more attention, participants should pay less attention to time and, consequently, time should be underestimated. Therefore, the main prediction was that participants would underestimate the duration of sexual taboo-word stimuli compared with low- and higharousal word stimuli. To build consistency across the present and recent research studies (e.g., Droit-Volet et al., 2004), the temporal bisection task was used. In addition, to limit the possible effects of strategic counting (Grondin, Meilleur-Wells, \& Lachance, 1999), relatively short $(<2 \mathrm{sec})$ stimuli durations were used. To test whether the effects are due to general arousal, the effects were compared with the effects recorded for high- and low-arousal positive and negative words. Furthermore, to control for the fact that emotional words form a tight semantic category, all effects were compared with a category-related neutral set of words.

\section{METHOD}

\section{Participants}

Forty psychology students ( 5 males $[M=20$ years; $S D=1.22]$ and 35 females $[M=19.69 ; S D=2.82])$ from the University of Hull took part in exchange for course credit.

\section{Stimuli and Apparatus}

Stimuli were 168 words ${ }^{1}$ selected from those that Janschewitz (2008) had collected and rated for valence, arousal, imageability, personal use, offensiveness, tabooness, and familiarity. Stimuli were grouped into six 28-word categories: high-arousal negative, high-arousal positive, low-arousal negative, low-arousal positive, category-related neutral, and sexual taboo. The mean and standard deviation of the ratings (collected by Janschewitz, 2008) for each word type are displayed in Table 1. Nine separate one-way ANOVAs were run to test for differences in word length, number of syllables, valence, arousal, imageability, personal use, offensiveness, tabooness, and familiarity between the word types. The $F$ and $p$ values for each ANOVA are displayed in Table 1. Post hoc analyses were carried out using the Student-Newman-Keuls formula. The findings support the assignment of the words to specific categories; the ratings were the same as those reported by Janschewitz, except that the taboo words were rated as more imageable than were the negative and positive words but significantly less imageable than were category-related neutral words. The word types did not differ in terms of either number of syllables or length.

The stimuli were presented in 16-point Arial font at the center of a 17 -in. computer monitor $(1,024 \times 768$ pixels, $60 \mathrm{~Hz})$ connected to a $1-\mathrm{GHz}$ Pentium-based computer. Stimulus presentation and data collection were controlled by E-Prime software (Schneider, Eschman, \& Zuccolotto, 2002).

Table 1

Means and Standard Deviations of the Ratings (Collected by Janschewitz, 2008) for Sexual Taboo, High-Arousal Negative, High-Arousal Positive, Low-Arousal Negative, Low-Arousal Positive, and Category-Related Neutral Words

\begin{tabular}{|c|c|c|c|c|c|c|c|c|c|c|c|c|c|c|}
\hline \multirow[b]{2}{*}{ Rating } & \multirow[b]{2}{*}{$F$} & \multirow[b]{2}{*}{ Significance } & \multicolumn{2}{|c|}{$\begin{array}{l}\text { High- } \\
\text { Arousal } \\
\text { Negative }\end{array}$} & \multicolumn{2}{|c|}{$\begin{array}{c}\text { Low- } \\
\text { Arousal } \\
\text { Negative }\end{array}$} & \multicolumn{2}{|c|}{$\begin{array}{l}\text { High- } \\
\text { Arousal } \\
\text { Positive }\end{array}$} & \multicolumn{2}{|c|}{$\begin{array}{l}\text { Low- } \\
\text { Arousal } \\
\text { Positive }\end{array}$} & \multicolumn{2}{|c|}{$\begin{array}{c}\text { Category- } \\
\text { Related } \\
\text { Neutral }\end{array}$} & \multicolumn{2}{|c|}{ Taboo } \\
\hline & & & $M$ & $S D$ & $M$ & $S D$ & $M$ & $S D$ & $M$ & $S D$ & $M$ & $S D$ & $M$ & $S D$ \\
\hline Letters & 0.27 & .9267 & 6.07 & 1.25 & 5.93 & 1.51 & 5.82 & 1.72 & 5.82 & 1.54 & 6.25 & 1.96 & 5.93 & 1.92 \\
\hline Syllables & 0.96 & .4433 & 1.83 & 0.66 & 1.93 & 0.77 & 1.64 & 0.73 & 1.79 & 0.63 & 1.96 & 0.96 & 2.04 & 0.79 \\
\hline Personal use & 6.64 & $<.0001$ & 4.63 & 0.86 & 4.71 & 1.21 & 5.08 & 1.22 & 4.85 & 0.82 & 4.59 & 1.16 & 3.58 & 1.05 \\
\hline Familiarity & 3.43 & .0057 & 5.55 & 0.72 & 5.50 & 1.10 & 5.75 & 0.98 & 5.45 & 0.70 & 5.02 & 0.99 & 4.90 & 1.07 \\
\hline Offensiveness & 38.88 & $<.0001$ & 1.47 & 0.35 & 1.50 & 0.54 & 1.03 & 0.02 & 1.02 & 0.04 & 1.02 & 0.01 & 2.59 & 1.09 \\
\hline Tabooness & 168.20 & $<.0001$ & 1.82 & 0.57 & 1.69 & 0.66 & 1.08 & 0.13 & 1.08 & 0.12 & 1.03 & 0.04 & 5.33 & 1.41 \\
\hline Valence & 171.72 & $<.0001$ & 3.13 & 0.48 & 3.26 & 0.52 & 6.57 & 0.59 & 6.70 & 0.56 & 5.12 & 0.21 & 4.11 & 1.12 \\
\hline Arousal & 102.55 & $<.0001$ & 3.30 & 0.49 & 2.68 & 0.52 & 3.11 & 0.61 & 2.86 & 0.64 & 1.53 & 0.30 & 4.97 & 0.82 \\
\hline Imageability & 14.45 & $<.0001$ & 4.12 & 1.51 & 4.19 & 1.68 & 4.70 & 1.87 & 4.57 & 2.24 & 7.33 & 1.03 & 5.65 & 1.68 \\
\hline
\end{tabular}




\section{Design and Procedure}

The procedure was similar to that described in earlier research (Droit-Volet et al., 2004; Tipples, 2008). Participants were trained initially to discriminate "short" ( $400 \mathrm{msec})$ from "long" $(1,600 \mathrm{msec})$ stimulus durations. On the first eight trials, a string of consonant letters appeared for either a short or long duration in a fixed sequence (e.g., long-short-long-short . . .). On each trial, one of eight letter strings (e.g., GHFTYH) was assigned randomly (without replacement) to the short or long durations. Participants were informed that the letter string would appear in this sequence and were asked to indicate whether the stimulus appeared for either a short or long duration by pressing one of two labeled keys on a QWERTY keyboard (the " $\mathrm{z}$ " and " $\mathrm{m}$ " keys were used). The response mapping (e.g., " $z$ " for short durations and " $m$ " for long durations) was counterbalanced across participants. Following a response, participants were presented with visual feedback for both correct ("yes") and incorrect ("no") decisions. The feedback appeared in the center of the screen for $2 \mathrm{sec}$ and was followed by an intertrial interval that could vary (according to a uniform random distribution), on each trial, in duration from 1 to $3 \mathrm{sec}$. After the initial training phase, there was a short break followed by a test session, during which letter strings were presented for a further eight trials in a new random order for each participant. During this phase, participants continued to indicate whether the letter string appeared for either the short or long stimulus duration. Participants continued to receive feedback in this phase, after which there was a short break followed by the main phase.

In the main phase, stimuli were presented for one of seven durations that included the standard durations (400 and 1,600 msec) and a further five intermediate durations $(600,800,1,000,1,200$, and $1,400 \mathrm{msec}$ ). Trials were separated by the same randomized intertrial intervals as were used in the training phase. The main phase was split into two blocks with 168 trials in each block. Each word was presented once within each block. Within each block, for each word type, there were four repetitions of the seven durations. Each word was randomly assigned (without replacement) to one of these durations. For each participant, a new random trial order was created within each block. Participants were asked to look at the stimulus and indicate whether it appeared for a duration that was closer to either the short or long duration that they had learned earlier. Feedback was not given during the main test phase.

\section{RESULTS}

\section{Data Analyses}

Prior to analysis of group-averaged data, a 7-point psychometric function for each participant (averaged across word type) was fitted to the cumulative normal distribution. The resultant $r^{2}$ values ranged from .89 to $.95(M=$ $.92, S D=.01)$.

For each participant, the mean proportion of "long" responses as a function of word type and duration were calculated. In addition, the BP and Weber ratio (WR) were calculated separately for each participant and for each word type. The BP refers to point of subjective equality (.5 point on the psychometric function) and was calculated using the method of least squares from the intercept and slope parameters of regression of $p_{\text {long }}$ onto stimulus duration (for more details, see Gescheider, 1985, p. 41). The WR measures temporal sensitivity and is calculated by dividing half the difference between the upper difference limen ( $\left.p_{\text {long }}[.75]\right)$ and the lower difference limen ( $p_{\text {long }}[.25]$ ) by the BP. All post hoc analyses were carried out using the Student-Newman-Keuls formula.
The mean proportion of "long" responses as a function of duration for nontaboo and taboo words is shown in Figure 1 . The nontaboo word category was created by calculating the mean proportion of "long" responses for the nontaboo words (high-arousal negative, high-arousal positive, low-arousal negative, low-arousal positive, and neutral [category] words). Figure 1 illustrates the main findings of this experiment: The mean proportion of "long" responses was lower for the taboo words than for the nontaboo words, and the function for the taboo words crosses the point of subjective equality (.5) at an earlier duration than does that for the other words. In addition, Figure 1 shows that the functions for nontaboo and taboo words formed an S-shaped curve, as predicted for normally distributed data.

A 7 (duration) $\times 6$ (word type) within-subjects ANOVA was used to analyze the mean proportion of "long" responses. The analysis revealed main effects of word type $\left[F(5,195)=4.28, p=.001, \eta_{\mathrm{p}}^{2}=.15\right]$ and duration $\left[F(6,234)=757.44, p<.0001, \eta_{\mathrm{p}}^{2}=.95\right]$. The main effect of duration showed that the mean proportion of "long" responses increased with the duration to be estimated. The interaction between word type and duration approached significance $[F(30,1170)=1.38, p=$ $\left..08, \eta_{\mathrm{p}}^{2}=.03\right]$. The effect of word type was not significant in either the 400-msec $[F(5,195)=0.40, p=.84$, $\left.\eta_{\mathrm{p}}^{2}=.01\right]$ or the $1,600-\mathrm{msec}[F(5,195)=0.52, p=.75$, $\left.\eta_{\mathrm{p}}^{2}=.01\right]$ duration conditions. The effect of word type remained significant after the short $(400-\mathrm{msec})$ and long $(1,600$-msec $)$ durations were removed $[F(5,195)=4.45$, $\left.p=.0007, \eta_{\mathrm{p}}^{2}=.1\right]$. Student-Newman-Keuls post hoc analyses of the main effect of word type for the durations ranging from 600 to $1,400 \mathrm{msec}$ showed that participants underestimated the duration of taboo words relative to

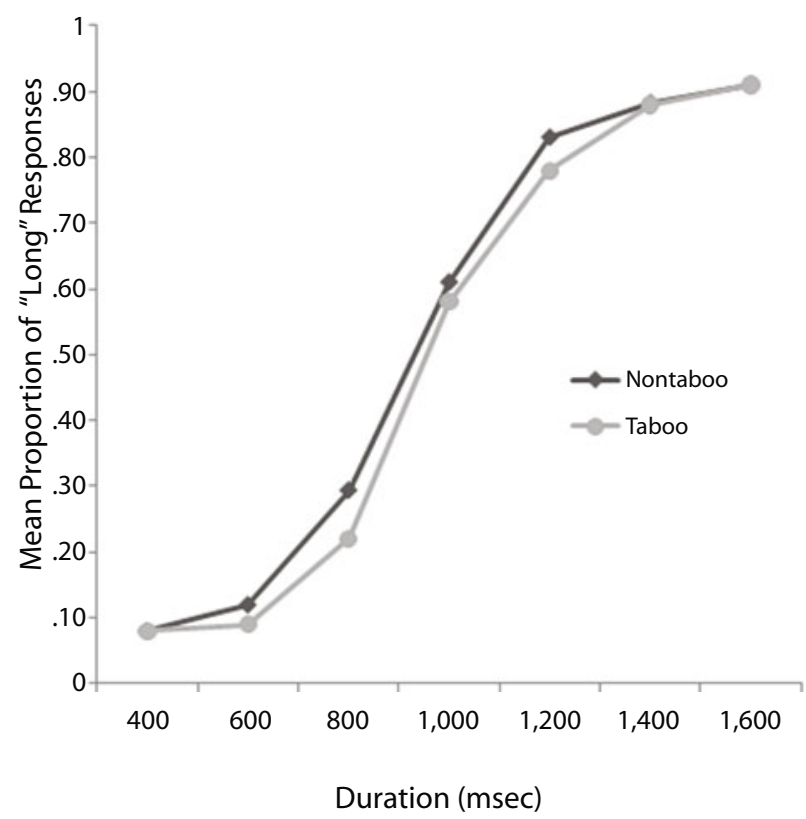

Figure 1. The mean proportion of "long" responses as a function of duration for nontaboo and taboo words. 
the other word types: The proportion of "long" responses was lower for taboo words $(M=.51, S D=.35)$ than for neutral words $(M=.54, S D=.34)$, high-arousal pleasant words $(M=.55, S D=.34)$, high-arousal unpleasant words $(M=.54, S D=.33)$, low-arousal pleasant words $(M=.56, S D=.34)$, and low-arousal unpleasant words $(M=.55, S D=.33)$.

BP and WR. A one-way within-subjects ANOVA was conducted to compare the effect of word type on the BP indices and WRs. The mean BP and standard error bars for each of the word types (high-arousal negative, high-arousal positive, low-arousal negative, low-arousal positive, neutral [category], taboo) are displayed in Figure 2. As can be seen in Figure 2, the BP was reached later for taboo words than for nontaboo words. Statistical analyses confirmed this impression. For the BP indices, there was also an effect of word type $\left[F(5,195)=4.38, p=.0008, \eta_{\mathrm{p}}^{2}=.10\right]$. Post hoc analyses showed that the BP was reached later for taboo words $(M=1,000, S D=82)$ than for all other word types (high-arousal negative words $[M=971, S D=85]$, high-arousal positive words $[M=967, S D=85]$, lowarousal negative words $[M=965, S D=79]$, low-arousal positive words $[M=957, S D=78]$, and category-related neutral words $[M=971, S D=85])$.

The effect of word type approached significance for the WRs $\left[F(5,195)=2.15, p=.06, \eta_{\mathrm{p}}^{2}=.05\right]$. The WR was lower (indicating greater sensitivity) for taboo words
$(M=.26, S D=.03)$ than for other word types (higharousal negative words $[M=.28, S D=06]$, high-arousal positive words $[M=.27, S D=.04]$, low-arousal negative words $[M=.28, S D=.04]$, low-arousal positive words $[M=.27, S D=.04]$, and category-related neutral words $[M=.27, S D=.04])$.

\section{DISCUSSION}

The present findings are consistent with the hypothesis that sexual taboo stimuli receive more attention: Individuals underestimated the duration of sexual taboo stimuli compared with category-related neutral words and, also, high- and low-arousal negative and positive words. The interpretation given here is that, when participants saw sexual taboo words, attention was drawn away from temporal information to the emotional meaning of the stimuli, and subsequently, elapsed time was underestimated. The data can also be interpreted in terms of the mechanisms that operate within a hypothetical internal clock (e.g., Gibbon et al., 1984; for a review, see Lejeune, 1998). Attention is thought to modulate several components of the internal clock, including the width of the switch opening, the frequency with which the switch opens and closes, and the interaction between decision processes and reference memory. Sexual taboo words may have affected the operation of a switch mechanism connecting the pacemaker to the accumulator.

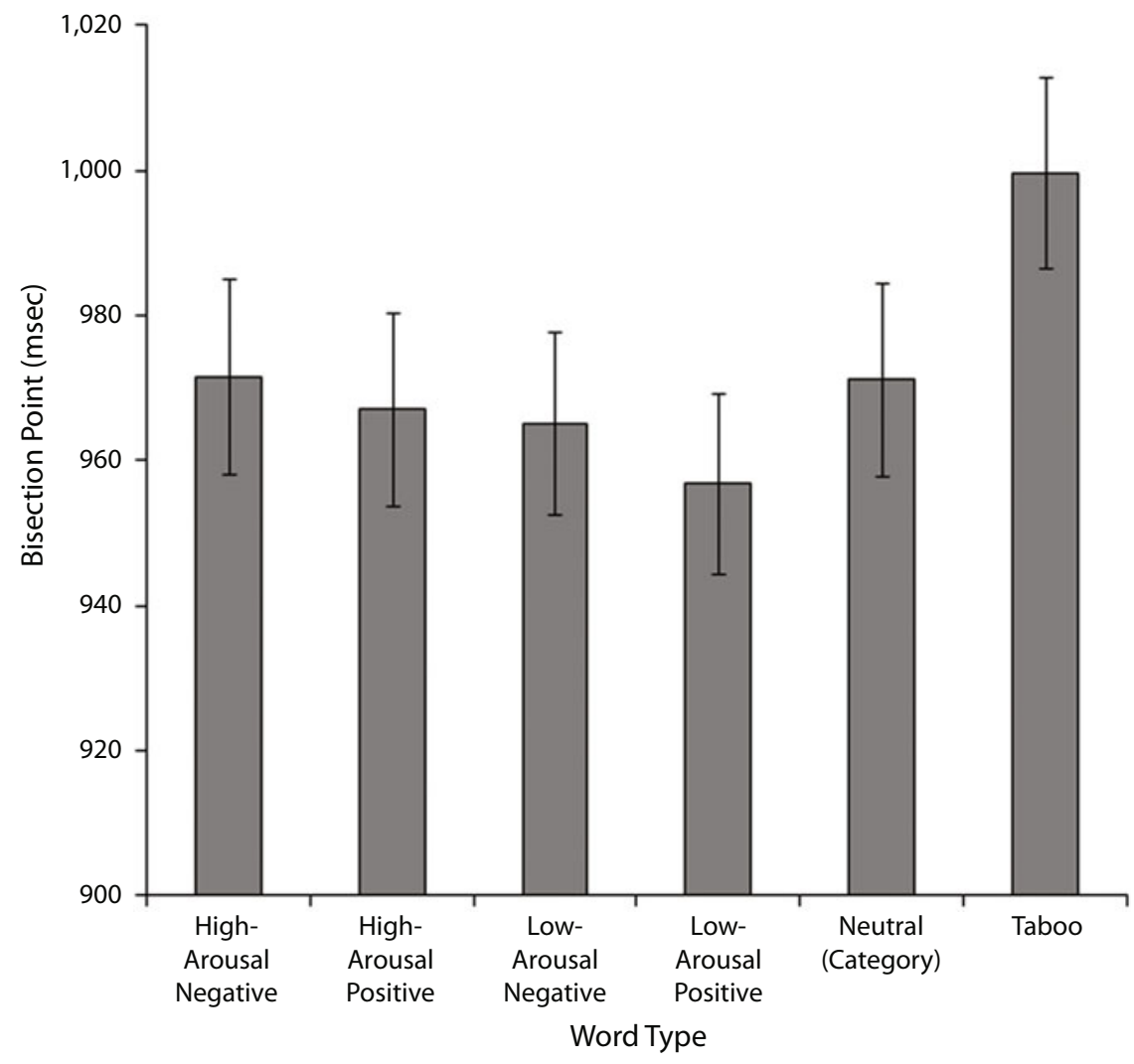

Figure 2. The mean bisection point, in milliseconds, and standard error bars for each of the word types (high-arousal negative, high-arousal positive, low-arousal negative, low-arousal positive, neutral [category], taboo). 
Specifically, the switch may have remained open longer following the presentation of sexual taboo words than following presentation of other word types, leading to a loss of counted pulses and an underestimation of time.

One interpretation of the present findings is that other processes in addition to high arousal are required to trigger attentional processes to words and subsequently to lead individuals to underestimate time. What additional processes may have triggered an attentional response for taboo words? A personal- or goal-relevance check (Scherer, 2001), in addition to increased arousal, may be necessary to trigger an attentional response. Such an explanation fits with findings of studies that have examined the effects of emotional words on attention. Attentional biases to emotional words seldom occur, unless the words are matched to the concerns of the individual being tested (for a review, see Williams et al., 1996). The effects may occur for sexual stimuli in nonselected participant groups because sexual images and sexual taboo words are arousing and also tap important concerns for all humans (e.g., disease, pregnancy, rape, incest, betrayal; Pinker, 2007). Indeed, in support of attentional processes operating for sexual stimuli, in the only existing study of the effects of sexual pictures on time perception (Angrilli et al., 1997), participants judged the duration of high-arousal sexual pictures as shorter than the duration of high-arousal negative pictures. In short, the effects agree with the idea that a relevance check is required for emotional meaning to receive greater attention and subsequently for time to be underestimated.

In addition to underestimation, temporal sensitivity in the form of the WR was lower (albeit nonsignificantly) for sexual taboo words than for other word types. This enhanced sensitivity effect is in keeping with other facilitatory effects for taboo words, including enhanced attention (Anderson, 2005) and better memory for the color and location of taboo word stimuli (Hadley \& MacKay, 2006; MacKay \& Ahmetzanov, 2005; MacKay et al., 2004). A lower WR indicates that individuals were more sensitive to changes in duration (the psychometric curve is steeper) when viewing sexual taboo words than when viewing other word types. Increased sensitivity typically is interpreted as reflecting an increase in the rate of the pacemaker (see, e.g., Grondin \& Rammsayer, 2003) and, therefore, does not agree with the idea put forward here that attention was focused away from time keeping. One possibility is that, although taboo words increase the rate of the pacemaker, such effects are not sufficiently strong to counteract the effects of taboo words on attention. One goal for future research will be to establish whether increased sensitivity can be replicated across a range of time-estimation tasks (Wearden, 2008).

One shortcoming of the present study is that only one range of durations was used. The use of two or more ranges of durations is important for testing the additive nature of attention-based effects and the multiplicative nature of arousal-based effects. If taboo stimuli hold attention by delaying the closing of an attention-governed switch, the effects should remain constant across dura- tions - the effects will be additive with real time. However, there is some evidence that arousal-based processing may decrease at longer durations. For example, for auditory stimuli (Noulhiane et al., 2007), overestimation effects were not observed at the longer durations $(>2 \mathrm{sec})$. Similarly, for picture stimuli (Angrilli et al., 1997), temporal overestimation for high-arousal unpleasant slides occurred when the pictures were displayed for $2 \mathrm{sec}$ but not for longer durations. One possibility mentioned elsewhere (Angrilli et al., 1997; Droit-Volet \& Meck, 2007) is that activation (arousal) decreases with time, allowing for a greater influence due to attention, and subsequently, for the elimination of overestimation. In short, a goal for future research is to further test the idea that attentional, and not other, processes (including memory and decision processes) that are thought to affect the internal clock mediate the effects of emotion on time.

Overall, the present findings support the idea that sexual taboo stimuli receive more attention - time flies when one is reading sexual taboo words.

\section{AUTHOR NOTE}

I thank three anonymous reviewers for their useful comments on a previous version of the manuscript. Address correspondence concerning this article to J. Tipples, Department of Psychology, University of Hull, Hull HU6 7RX, England (e-mail: j.tipples@hull.ac.uk).

\section{REFERENCES}

Anderson, A. K. (2005). Affective influences on the attentional dynamics supporting awareness. Journal of Experimental Psychology: General, 134, 258-281.

Angrilli, A., Cherubini, P., Pavese, A., \& Manfredini, S. (1997). The influence of affective factors on time perception. Perception $\&$ Psychophysics, 59, 972-982.

Arnell, K. M., Killman, K. V., \& FiJavz, D. (2007). Blinded by emotion: Target misses follow attention capture by arousing distractors in RSVP. Emotion, 7, 465-477

Burle, B., \& CAsini, L. (2001). Dissociation between activation and attention effects in time estimation: Implications for internal clock models. Journal of Experimental Psychology: Human Perception \& Performance, 27, 195-205. doi:10.1037/0096-1523.27.1.195

Droit-Volet, S., Brunot, S., \& Niedenthal, P. M. (2004). Perception of the duration of emotional events. Cognition \& Emotion, 18, 849858. doi:10.1080/02699930341000194

Droit-Volet, S., \& Meck, W. H. (2007). How emotions colour our perception of time. Trends in Cognitive Sciences, 11, 504-513. doi:10 1016/j.tics.2007.09.008

Effron, D. A., Niedenthal, P. M., Gil, S., \& Droit-Volet, S. (2006). Embodied temporal perception of emotion. Emotion, 6, 1-9.

Gescheider, G. A. (1985). Psychophysics: Method, theory, and practice (2nd ed.). Hillsdale, NJ: Erlbaum.

Gibbon, J., Church, R. M., \& Meck, W. H. (1984). Scalar timing in memory. In J. Gibbon \& L. Allan (Eds.), Timing and time perception (Annals of the New York Academy of Sciences, Vol. 423, pp. 52-77). New York: New York Academy of Sciences.

Gil, S., Niedenthal, P. M., \& Droit-Volet, S. (2007). Anger and time perception in children. Emotion, 7, 219-225.

Grondin, S., Meilleur-Wells, G., \& Lachance, R. (1999). When to start explicit counting in a time-intervals discrimination task: A critical point in the timing process of humans. Journal of Experimental Psychology: Human Perception \& Performance, 25, 993-1004. doi:10.1037/0096-1523.25.4.993

Grondin, S., \& RAMmsayer, T. (2003). Variable foreperiods and temporal discrimination. Quarterly Journal of Experimental Psychology, 56A, 731-765. doi:10.1080/02724980244000611

Hadley, C. B., \& MaCKay, D. G. (2006). Does emotion help or hinder 
immediate memory? Arousal versus priority-binding mechanisms. Journal of Experimental Psychology: Learning, Memory, \& Cognition, 32, 79-88. doi:10.1037/0278-7393.32.1.79

JANSCHEWITZ, K. (2008). Taboo, emotionally valenced, and emotionally neutral word norms. Behavior Research Methods, 40, 1065-1074. doi:10.3758/BRM.40.4.1065

LeJeune, H. (1998). Switching or gating? The attentional challenge in cognitive models of psychological time. Behavioural Processes, 44, 127-145.

MacKay, D. G., \& Ahmetzanov, M. V. (2005). Emotion, memory, and attention in the taboo Stroop paradigm: An experimental analogue of flashbulb memories. Psychological Science, 16, 25-32. doi:10.1111/j.0956-7976.2005.00776.x

MacKay, D. G., Shafto, M., Taylor, J. K., Marian, D. E., Abrams, L., \& DYER, J. R. (2004). Relations between emotion, memory, and attention: Evidence from taboo Stroop, lexical decision, and immediate memory tasks. Memory \& Cognition, 32, 474-488.

Mondillon, L., Niedenthal, P. M., Gil, S., \& Droit-Volet, S. (2007). Imitation of in-group versus out-group members' facial expressions of anger: A test with a time perception task. Social Neuroscience, 2, 223-237. doi:10.1080/17470910701376894

Noulhiane, M., Mella, N., Samson, S., Ragot, R., \& Pouthas, V. (2007). How emotional auditory stimuli modulate time perception. Emotion, 7, 697-704. doi:10.1037/1528-3542.7.4.697

Pinker, S. (2007). The stuff of thought. Cambridge, MA: Harvard University Press.

SCHERER, K. R. (2001). Appraisal considered as a process of multilevel sequential checking. In K. R. Scherer, A. Schorr, \& T. Johnstone (Eds.), Appraisal processes in emotion: Theory, methods, research (pp. 92-120). Oxford: Oxford University Press.

Schimmack, U. (2005). Attentional interference effects of emotional pictures: Threat, negativity, or arousal? Emotion, 5, 55-66.
Schneider, W., Eschman, A., \& Zuccolotto, A. (2002). E-Prime user's guide. Pittsburgh, PA: Psychology Software Tools, Inc.

Sharma, D., \& McKenna, F. P. (2001). The role of time pressure in the emotional Stroop task. British Journal of Psychology, 92, 471-481. doi:10.1348/000712601162293

TIPPLES, J. (2008). Negative emotionality influences the effects of emotion on time perception. Emotion, 8, 127-131. doi:10.1037/1528 $-3542.8 .1 .127$

Tipples, J., \& Sharma, D. (2000). Orienting to exogenous cues and attentional bias to affective pictures reflect separate processes. British Journal of Psychology, 91, 87-97.

WeARDEN, J. H. (2008). Slowing down an internal clock: Implications for accounts of performance on four timing tasks. Quarterly Journal of Experimental Psychology, 61, 263-274. doi:10 $.1080 / 17470210601154610$

Wearden, J. H., Philpott, K., \& Win, T. (1999). Speeding and (.. . relatively . . .) slowing down an internal clock in humans. Behavioural Processes, 46, 63-73.

Williams, J. M. G., Mathews, A., \& MacLeod, C. (1996). The emotional Stroop task and psychopathology. Psychological Bulletin, 120, 3-24. doi:10.1037/0033-2909.120.1.3

ZAKAY, D., \& FALlaCH, E. (1984). Immediate and remote timeestimation-A comparison. Acta Psychologica, 57, 69-81. doi:10 1016/0001-6918(84)90054-4

\section{NOTE}

1. Words available on request from the author.

(Manuscript received April 22, 2009;

revision accepted for publication January 16, 2010.) 